\title{
PERSPECTIVAS PARA O ENSINO DE LÍNGUA MATERNA POR MEIO DE PRÁTICAS DE LETRAMENTO: INTERVENÇÃO PEDAGÓGICA EM ESCOLA PARAENSE
}

\section{PERSPECTIVES FOR TEACHING OF THE NATIVE LANGUAGE THROUGH OF LITERACY PRACTICE: PEDAGOGICAL INTERVENTION IN PARAENSE SCHOOL}

Clébia do Socorro Salvador Maciel ${ }^{1}$

Resumo: Este artigo é resultado da pesquisa realizada numa escola da rede pública, de um município do interior do estado do Pará. Sua base se fundamentou na proposta do curso de mestrado direcionado a professores de ensino fundamental, denominado ProfLetras, que postulava a realização de um trabalho de natureza interpretativa e interventiva, cujo objeto de investigação fosse um problema da realidade escolar do docente. Assim, partindo das observações feitas, buscou-se, na proposta da dissertação, a constituição de ações que pudessem amenizar os problemas da realidade observada.

Palavras-chave: letramento; língua; ensino; ProfLetras

Abstract: This article is result of research carried out at a public school in a municipality in the interior of the Pará State. Its base was based on the proposal of the master course directed to elementary school teachers, called ProfLetras, which postulated the accomplishment of a work of an interpretive and interventional nature, whose object of investigation was a problem of the school reality of the teacher. Thus, based on the observations made, the proposal of the dissertation sought the constitution of actions that could soften the problems of the reality observed.

Keywords: literacy; language; teaching; ProfLetras

\section{Introdução}

Este artigo é resultado de uma dissertação de mestrado cujo objetivo foi realizar uma investigação acerca dos níveis de letramento de alunos concluintes do ensino fundamental, de uma escola do município de Soure-PA, visto que, nos últimos anos, os resultados das avaliações nacionais vinham indicando um baixo índice de competência leitora desses alunos, o que os mantinha apenas no nível mais básico de alfabetismo. O trabalho constituiu-se ainda de uma proposta de intervenção que visava melhorar os níveis de letramento encontrados nos alunos investigados e propor um ensino mais qualificado para a clientela da escola pesquisada.

\footnotetext{
1 Mestre pelo ProfLetras da Universidade Federal do Pará. Docente da rede pública paraense. E-mail: clebiamaciel@hotmail.com
} 
A natureza dessa pesquisa se fundamentou na proposta do curso de mestrado direcionado a professores de ensino fundamental da rede pública de ensino, denominado ProfLetras que postulava a realização de um trabalho de natureza interpretativa e interventiva, cujo objeto de investigação fosse um problema da realidade escolar do docente. Desta feita, buscou-se, em princípio, realizar uma observação das maiores dificuldades enfrentadas em sala de aula, quando se detectou como principal entrave para a aprendizagem dos alunos a dificuldade que apresentavam para realizar tarefas, até certo ponto simples, de interpretação textual e escrita.

Partindo dessa inquietação e, sendo a natureza do trabalho de caráter interventivo, buscou-se, na proposta da dissertação, a constituição de ações que pudessem amenizar tal realidade, por acreditar-se que qualquer tipo de ação que vise avanços para a educação brasileira deva partir da própria escola, de seus professores, uma vez que são eles que conhecem a realidade de seus alunos, de sua comunidade e, por conseguinte, podem trilhar os melhores caminhos para reverter o quadro em que se encontram.

Todo o conteúdo do trabalho foi dividido em quatro capítulos que abordaram os pressupostos teóricos que regem os fundamentos acerca das noções de alfabetização e letramento, considerados como um processo de aquisição da linguagem escrita e como aprimoramento da linguagem falada. Nesse sentido, a discussão abrangeu os conceitos e teorias sobre língua e suas manifestações (leitura e escrita), o que levou a discussão às considerações relacionadas à legislação educacional vigente e suas recomendações, bem como aos meios de avaliação nacional da educação.

Seguem ainda a especificações a respeito da metodologia utilizada para a realização da pesquisa, bem como as particularidades e características do tipo de pesquisa adotada. Nesse sentido abordaram-se as informações referentes aos sujeitos envolvidos, locus da pesquisa e dados quantitativos relevantes para a observação realizada; apresentação dos dados obtidos e descrição da primeira utilização da proposta (execução de um tópico da proposta de intervenção, realizada na turma observada, que serviu de base para a construção final da mesma). A esse tópico se seguem a apresentação da proposta de intervenção, sua base teórica específica e os passos dados para a sua realização.

\section{0 processo de alfabetização: leitura e escrita}


Em geral, é comum que as dificuldades existentes em turmas de ensino fundamental sejam atribuídas a uma alfabetização deficitária, recebida por parte dos alunos, entretanto, uma das propostas desse estudo foi mostrar exatamente o contrário, pois acredita-se que mesmo diante de problemas que venham a ocorrer durante o processo de alfabetização, o aluno tem meios de sanar tais dificuldades, cabendo ao professor (de todas as séries) buscar maneiras de ajudar esse aluno.

Sendo assim, no que diz respeito ao processo de alfabetização, o fato é que, ao término do $1^{\circ}$ nível do ensino fundamental ( $1^{\circ}$ ao $5^{\circ}$ ano), muitas crianças ainda não dominam as habilidades de leitura e escrita demandadas, passando para as séries seguintes com grandes restrições linguísticas (pouco domínio da escrita, dificuldades de compreensão durante a leitura, entre outras implicações). Esse nível escolar é considerado o responsável pela aquisição dessas duas competências, mas tais competências não se restringem a ele.

A alfabetização, vista em seu sentido próprio e específico, segundo Soares (2013, p.15), como correspondente ao "processo de aquisição do código escrito, das habilidades de leitura e escrita", vem apresentando grandes problemas no município de Soure (locus da pesquisa), uma vez que tais habilidades não fazem parte das práticas educacionais que as crianças dominam ao final do $1^{\mathrm{o}}$ ciclo escolar, o que acaba acarretando um problema para o ano subsequente, e que, em muitos casos, continua no decorrer de muitas séries, e quiçá, da vida inteira do aluno.

Para que se trace um objetivo, convém, primeiramente, eleger metas e estratégias. É preciso que essas duas perspectivas não sejam desenvolvidas de maneira distinta, e sim, paralelas e relacionadas, numa espécie de continuação (sequência), em que os conhecimentos técnicos sejam adquiridos e desenvolvidos dentro de uma visão crítica que insira o indivíduo num contexto histórico, cultural e social.

O baixo desempenho dos alunos nas atividades de leitura e escrita (seja no ensino fundamental ou médio) mostra que um dos grandes problemas apontados, inclusive por eles mesmos, é a dificuldade na compreensão da palavra escrita, inserida no texto em si. Tais dificuldades aparecem durante as práticas de leitura, quando se percebe o quanto parece complexo, para o aluno, a decifração de algumas palavras, e mais especificamente, a compreensão do significado dessa palavra e sua relação com o contexto em que ora se insere. São dificuldades de leitura que se refletem na escrita, uma vez que é impossível dissociar uma prática da outra, ou seja, o aluno que lê mal também escreve mal. 
Diante dessa realidade, percebida muitas vezes em alunos do ensino fundamental maior ( $6^{\circ}$ ao $9^{\circ}$ ano), o professor costuma se questionar sobre a alfabetização dessas crianças e, sem compreender corretamente o processo e suas dificuldades, tende, algumas vezes, a imputar sobre o aluno o fardo daquilo que não está se desenvolvendo a contento.

O uso da língua escrita nasce a partir de conhecimentos básicos, adquiridos nos primeiros anos de escolarização de uma pessoa, sendo desenvolvidos, segundo Lemle (2009), antes mesmo da alfabetização (em suas palavras, seriam cinco as capacidades necessárias para a alfabetização ${ }^{2}$ ). Desse modo, acredita-se que é importante partir da investigação desse processo, do ponto onde ele realmente começa (ou deveria começar), uma vez que o processo de alfabetização reflete em todos os níveis e séries que se seguem a ele. Ou seja, as habilidades de leitura e escrita, adquiridas e desenvolvidas a partir da alfabetização, percorrem e são necessárias para todos os demais níveis de ensino, sendo responsáveis pela maioria dos fatores que medem o sucesso ou o fracasso educacional de um aluno.

A criança que se inicia no processo de escolarização já é um falante capaz de entender e falar a língua portuguesa, com desembaraço e precisão, nas circunstâncias mais variadas de sua vida, mas não sabe escrever nem ler. Esses são novos usos da linguagem para ela, e é isso que ela espera da escola: aprender a utilizar essas modalidades, não só para conseguir decifrálas, mas para usá-las dentro das mais variadas práticas sociais.

Leitura e escrita são duas práticas sociais e, apesar de englobarem as atividades mecânicas de codificar e decodificar a língua escrita, não se restringem somente a isto. Segundo Soares (2013, p. 16), ler e escrever correspondem à “apreensão e compreensão de significados expressos em língua escrita (ler) ou expressão de significados por meio da língua escrita (escrever)". Essas duas habilidades permeiam o conceito de alfabetização, que corresponde ao processo que torna o indivíduo capaz de ler e escrever. Desse modo, pode-se pensar em alfabetização como um processo de compreensão e expressão do código escrito, em que o falante possa realizar as atividades mecânicas de ler e escrever e, além disso, refletir sobre esse código e se expressar por meio dele, atribuindo, desse modo, um caráter social ao processo. A partir dessa compreensão, pode-se falar em Letramento.

\section{Letramento}

\footnotetext{
${ }^{2}$ As cinco capacidades seriam: a ideia de símbolo, a discriminação das formas das letras, a discriminação dos sons da fala, a consciência da unidade palavra e a organização da página escrita. (LEMLE, 2009)
} 
Na perspectiva de desenvolvimento da língua (que se faz a partir da aquisição do código escrito, por meio da alfabetização), pode-se falar atualmente em letramento (ou níveis de letramento), definido por Soares (2012) como "resultado da ação de ensinar e aprender as práticas sociais de leitura e escrita; o estado ou condição que adquire um grupo social ou um indivíduo como consequência de ter-se apropriado da escrita e de suas práticas sociais" (SOARES, 2012, p. 39).

Ainda sobre essa concepção, a autora chama atenção para o fato de que,

ter-se apropriado da escrita é diferente de ter aprendido a ler e a escrever: aprender a ler e escrever significa adquirir uma tecnologia, a de codificar em língua escrita e de decodificar a língua escrita; apropriar-se da escrita é tornar a escrita 'própria', ou seja, é assumi-la como sua 'propriedade' (SOARES, 2012, p.39) - grifos da autora

Nem sempre estar alfabetizado significa estar em processo de letramento (porque este é permanente). Possuir as habilidades técnicas de leitura e escrita, não garante ao indivíduo o uso consciente destas. Quando o indivíduo se apossa dessas habilidades e, faz uso delas em suas relações sociais, ele se transforma, passa a agir sobre vários aspectos de sua vida, social, cultural, cognitivo, linguístico, como falante competente; ou seja, ele utiliza a leitura e a escrita dentro de práticas sociais, por meio de uma funcionalidade crítica e reflexiva.

Dentro dessa perspectiva, que aponta o letramento como um processo permanente de uso e aperfeiçoamento das práticas sociais de leitura e escrita, torna-se necessário falar em níveis de letramento, uma vez que este, tendo se iniciado na alfabetização, quando a criança adquire as habilidades de reconhecimento e representação do código escrito, estende-se por toda a vida. Desse modo, seria interessante, já nessa fase (alfabetização), iniciar-se a conscientização social do uso das atividades de ler e escrever, pois, de acordo com as considerações de Soares (2012), é possível alfabetizar letrando, isto é, pode-se ensinar crianças e adultos a ler, fazê-los adquirir o código escrito e a utilizá-lo para si e para os outros, a usar a palavra escrita em sua vida social. Nas palavras da autora: "Nosso problema não é apenas ensinar a ler e a escrever, mas também, e sobretudo, levar os indivíduos - crianças e adultos a fazer uso da leitura e da escrita, envolver-se em práticas sociais de leitura e de escrita" (SOARES, 2012, p. 58).

\section{A legislação educacional}


Durante o processo de escolarização, uma vez adquiridas as habilidades de leitura e escrita, a escola passa a desenvolvê-las, e tal desenvolvimento não se limita à uma série ou nível escolar, é um processo permanente que se estende para além da educação básica e, portanto, deve ser o ponto principal a ser focado nas práticas educacionais, visto que é o que assegura ao aluno sua elevação nos níveis de alfabetismo.

Em vista disso, acredita-se que a promoção de práticas educacionais que visam a aprendizagem e o desenvolvimento das habilidades de leitura e escrita pelas quais os alunos passam, em todos os níveis de ensino, pode ser extremamente válida para o bom desempenho destes, não só na disciplina de Língua Portuguesa, bem como em todas as outras e, consequentemente, no ensino como um todo. Essa é, inclusive, uma das recomendações da legislação educacional vigente.

Os Parâmetros Curriculares Nacionais (BRASIL, 1998), em sua apresentação inicial a respeito do ensino de língua portuguesa, registram o dever da escola em proporcionar aos alunos condições de ampliar o domínio que possuem de sua língua, para que estes alunos possam, durante os anos de vivência escolar,

\footnotetext{
ler e escrever conforme seus propósitos e demandas sociais; expressar-se apropriadamente em situações de interação oral diferentes daquelas próprias de seu universo imediato; refletir sobre os fenômenos da linguagem, particularmente os que tocam a questão da variedade linguística, combatendo a estigmatização, discriminação e preconceitos relativos ao uso da língua. (BRASIL, 1998, p.59)
}

Os PCN propõem que a leitura e a produção de textos, dentro da escola, sejam desenvolvidas de uma maneira adequada e útil ao universo escolar e à realidade social do aluno. Para isso, tomam como base as teorias sócio interacionistas e dos gêneros discursivos, a partir das ideias de Bakhtin (1979), muito presentes em toda a extensão do documento. Ainda dentro dessa perspectiva, os documentos oficiais (PCN) alertam para a necessidade de se trabalhar com uma grande variedade de gêneros, tanto orais quanto escritos, para propiciar aos alunos o maior número de situações de fala que ele, de fato, vá participar na vida.

Tais princípios vêm sendo amplamente difundidos não só em documentos oficiais relativos à educação, mas em muitas publicações de estudiosos que seguem essa linha de pensamento e servem de suporte para várias inovações no cenário educacional. Nesse sentido, é válido ressaltar as considerações de Schneuwly e Dolz (2004), que consideram o texto instrumento base para o ensino-aprendizagem de língua portuguesa e, acreditam ser por meio dos gêneros, que se estabelece a articulação entre as práticas sociais e os objetos escolares. Isso 
fomenta a ideia de que, para que o aluno realmente tenha um ensino de qualidade, este deve ser confrontado com gêneros que sejam (ou venham a ser) relevantes para a sua vida social.

Sendo assim, o foco do ensino de língua portuguesa deve ser os gêneros textuais, pois são eles que possibilitam o desenvolvimento da competência comunicativa do aluno, para o aprimoramento de seu desempenho nas mais diversas situações de comunicação, mesmo porque, são geralmente essas competências que são levadas em consideração nas avaliações nacionais, como a Prova Brasil, que traz em seu cerne uma relação de competências e habilidades necessárias para o aluno, de acordo com o nível escolar em que se encontre.

A Prova Brasil, que faz parte do sistema de avaliações do governo federal sobre a educação básica (SAEB), avalia, em língua portuguesa, seis temas centrais, subdivididos em quinze itens para o $5^{\circ}$ ano, e 21 para o $9^{\circ}$ ano do ensino fundamental. Na avaliação de língua portuguesa, o aluno deve demonstrar habilidades em questões ligadas a procedimentos de leitura, implicações de suporte, de gênero e/ou do enunciador na compreensão do texto, relação entre textos, coerência e coesão no processamento do texto, relações entre recursos expressivos e efeitos de sentido e variação linguística.

As questões são elaboradas com base nas propostas curriculares estaduais e municipais e nos Parâmetros Curriculares Nacionais - PCN (diretrizes elaboradas por disciplina pelo Governo Federal para orientar o conteúdo trabalhado nas escolas do país). Em Língua Portuguesa (cujo foco é a leitura), são avaliadas habilidades e competências definidas em unidades chamadas descritores, agrupadas em tópicos que compõem a Matriz de Referência dessa disciplina.

As Matrizes de Língua Portuguesa da Prova Brasil e do SAEB estão estruturadas em duas dimensões. Na primeira dimensão, que é "objeto do conhecimento”, foram elencados seis tópicos, relacionados às habilidades desenvolvidas pelos estudantes. A segunda dimensão da matriz de Língua Portuguesa refere-se às "competências" desenvolvidas pelos estudantes. E, dentro desta perspectiva, foram elaborados descritores específicos para cada um dos seis tópicos mencionados anteriormente, diferentes para cada um dos níveis de ensino avaliados.

Dentre os descritores determinados pelas habilidades e competências encontram-se situações que mais uma vez enfatizam o uso consciente da língua, a capacidade leitora dos alunos dentro de uma perspectiva crítica e empírica, além de elementos que enfatizam sua conscientização linguística, e que levam em consideração o texto (ou enunciado), o seu 
interlocutor, o seu contexto de produção e ele mesmo, enquanto produtor do texto, dotado de intenções e expectativas.

Em suma, são procedimentos avaliativos que consideram uma nova visão de ensino, que se desassocia do ensino tradicionalista de repasse de regras gramaticais infrutíferas, que usa o texto como mero instrumento para o ensino de taxonomias gramaticais, e a produção de texto unicamente como pretexto para a correção de erros ortográficos.

Não se tem com isso a premissa de que o ensino da gramática é desnecessário e sem sentido; quanto a isto, os PCN alertam que

\begin{abstract}
Na perspectiva de uma didática voltada para a produção e interpretação de textos, a atividade metalinguística deve ser instrumento de apoio para a discussão dos aspectos da língua que o professor seleciona e ordena no curso do ensino-aprendizagem. Assim, não se justifica tratar o ensino gramatical desarticulado das práticas de linguagem. É o caso, por exemplo, da gramática que, ensinada de forma descontextualizada, tornou-se emblemática de um conteúdo estritamente escolar, do tipo que só serve para ir bem na prova e passar de ano. [...] Em função disso, discutese se há ou não necessidade de ensinar gramática. Mas essa é uma falsa questão: a questão verdadeira é o que, para que e como ensiná-la. (BRASIL, 1998, p. 28)
\end{abstract}

A crítica não reside no fato de se ensinar gramática ou não, mas em como ensiná-la. Em geral, o que se tem ensinado está muito aquém do que se deveria ensinar, e isso acarreta diversos problemas, para alunos, professores e demais envolvidos no processo educacional. São situações que, por mais que pareçam simples, correspondem a uma grande problemática enfrentada pela comunidade escolar, que ainda se vê limitada ao ensino metalinguístico, mas que, aos poucos, vem apresentando alguns avanços e, gradativamente, tende a passar de um estágio de obscuridade e fronteiras, à luz da liberdade e do prazer, de ensinar e aprender.

\title{
4 Procedimentos metodológicos da pesquisa
}

Para conduzir a investigação e análise do objeto dessa pesquisa, buscou-se traçar um procedimento metodológico aos moldes da linha da pesquisa-ação ${ }^{3}$, por esta constituir uma forma de pesquisa interativa, que busca detectar um problema e resolvê-lo em conjunto com os sujeitos envolvidos na questão investigada. Tal escolha se justifica ainda, em face de a temática

\footnotetext{
${ }^{3}$ A pesquisa-ação, segundo Franco (2005), tem seus princípios difundidos por Kurt Lewis (1946), e é a ele que se atribui a origem do termo. Caracteriza-se, como uma forma de pesquisa interativa que, tendo detectado uma situação problema, busca compreender suas causas e produzir mudanças. Desse modo, tem como foco principal a resolução de um problema que esteja prejudicando um indivíduo ou um grupo de indivíduos, sejam eles participantes de instituições, escolas, ou organizações comunitárias.
} 
proposta ter surgido a partir das inquietações docentes sobre a deficiência da capacidade leitora (e compreensiva) dos alunos concluintes do ensino fundamental e, consequentemente, da necessidade de se buscar uma melhoria no nível em que se encontravam os alunos do $9^{\circ}$ ano da Escola Gasparino.

Desse modo, os procedimentos descritos a seguir correspondem aos passos dados durante a investigação realizada na escola que constituiu o locus da pesquisa, os quais ocorreram no período de maio a dezembro de 2014, e referem-se tanto à pesquisa dos dados em si, quanto aos procedimentos interventivos (nesta ordem). Estes últimos foram construídos conjuntamente com os professores das turmas pesquisadas (as propostas eram apresentadas para as professoras e estas contribuíam com sugestões, recortes ou inserções).

\subsection{Ambientação da pesquisa}

O locus da pesquisa foi o município de Soure, localizado na Ilha de Marajó, arquipélago do estado do Pará. Esse município possui uma população de aproximadamente 23.000 habitantes (segundo o censo de 2010, IBGE 4 ; a estimativa de 2014 é de 24.076), e IDH (índice de desenvolvimento humano) de 0,615 (2010), tendo relativo crescimento na área da educação segundo esses dados, em comparação a última média realizada em 2000.

Soure conta com 19 escolas, sendo três da rede estadual, que atendem o ensino fundamental maior ( $6^{\circ}$ a $9^{\circ}$ ano) e o ensino médio; e 16 escolas da rede municipal, sendo 8 localizadas na zona urbana e 8 na zona rural (incluindo localidades de fazendas e praias). $\mathrm{O}$ município conta ainda com duas escolas de educação infantil, que atende o maternal (I e II níveis) e o jardim (I e II níveis).

As 16 escolas municipais atendem crianças numa faixa etária de vai dos seis até aproximadamente catorze anos (a partir dos 15 anos os alunos que ainda encontram-se nesse nível de ensino frequentam turmas de Educação de Jovens e Adultos - EJA - , a não ser que façam parte do grande percentual de alunos que se encontram em distorção idade/série).

A pesquisa foi ambientada na Escola Estadual de Ensino Fundamental e Médio Prof. Gasparino Batista da Silva, localizada na travessa 14 , entre $5^{\mathrm{a}}$ e $6^{\mathrm{a}}$ ruas do bairro centro. A escola funciona em três turnos (matutino, vespertino e noturno), atendendo o ensino fundamental maior ( $6^{\circ}$ ao $9^{\circ}$ ano) e o ensino médio. A modalidade educacional é o ensino

\footnotetext{
4 Disponível em: http://www.cidades.ibge.gov.br/xtras/perfil.php?lang=\&codmun=150790 / Acesso em: $20 / 02 / 2015$
} 
regular e a EJA. A escola conta com um trio gestor (uma diretora e dois vice-diretores), dez especialistas em educação, sendo quatro lotados no turno da manhã, três à tarde e três à noite. Atende, aproximadamente, 1.600 alunos, distribuídos em 43 turmas, sendo: 15 turmas de manhã; 15 à tarde e 13 à noite 5 .

\subsection{Os sujeitos do processo}

A pesquisa contou com a participação de dois agentes altamente envolvidos no processo educacional: alunos e professores. Como a investigação foi realizada no $9^{\circ}$ ano do ensino fundamental (aqui denominado $8^{\mathrm{a}}$ série), foram observadas apenas as turmas dessa série, sendo três no total, duas no turno da manhã e uma no turno da tarde. As duas turmas da manhã tem a mesma professora, para a disciplina de Língua Portuguesa, e a da tarde, uma outra professora. A amostra da pesquisa ficou assim composta: 02 professoras e 94 alunos (36 na turma A, 34 na turma B - manhã; e 24 na turma $\mathrm{C}$ - tarde).

As duas professoras pesquisadas são graduadas em Letras (habilitação em língua portuguesa) e, passarão a ser denominadas aqui como professora das turmas A e B, e professora da turma C. A professora das turmas A e B é responsável pelas duas turmas da manhã, somando com elas um total de 280 horas (carga horária total), exclusivamente no ensino fundamental; não possui especialização ou outros cursos de formação continuada; tem nove anos de graduação e nove de docência, sendo dois anos em esfera particular e sete em esfera pública).

A professora da turma C possui uma carga horária total de 260 horas, sendo $55 \mathrm{~h}$ no ensino fundamental (com turmas regulares e de EJA), e 205h no ensino médio. Da carga horária destinada ao médio, apenas 160 horas são destinadas às aulas de Língua Portuguesa, o restante (45h) são de Literatura. A professora tem oito anos de graduada e possui especialização em Ensino e aprendizagem em Língua Portuguesa. Seu tempo total de docência é de seis anos, cinco deles na rede estadual de ensino.

Os alunos das três turmas têm, em média, de 14 a 17 anos de idade. Todos cursaram sempre a escola pública e vêm de famílias relativamente carentes, algumas com sérios problemas estruturais de ordem familiar.

Para a obtenção dos dados da pesquisa, um dos procedimentos adotados foi a realização de rodas de conversa com os alunos, nas quais se procurou levantar algumas informações referentes às práticas de leitura e escrita dos alunos, bem como sobre seu desempenho escolar

\footnotetext{
${ }^{5}$ Esses dados correspondem à lotação de 2014
} 
e suas opiniões acerca das aulas de língua portuguesa. Com as professoras pesquisadas adotouse o seguinte procedimento: conversa inicial, na qual se explicou o fundamento e os objetivos do trabalho de investigação e, em seguida, cada uma passou a relatar suas experiências de sala de aula e, após essa etapa, sugeriu-se às professoras que fizessem uma espécie de diário, no qual descrevessem, de modo generalizante, suas rotinas profissionais.

\subsection{Resultados da pesquisa e análise dos dados}

A escola Gasparino participou da última avaliação nacional de rendimento escolar (Prova Brasil), realizada em 2013, bem como nos anos iniciais da avaliação (2005, 2007 e 2009). Em 2011, segundo informações da administração da escola, a mesma não participou da avaliação, em função de um erro no repasse de dados para o sistema do MEC.

Os dados do IDEB dos últimos anos da escola mostram que, em âmbito nacional, o índice de desenvolvimento da educação básica se manteve em crescente avanço, entretanto, na última edição não alcançou a meta pretendida. Já as notas da esfera estadual demonstram uma oscilação de baixa, nas edições de 2007 e 2013, mantendo-se sempre abaixo da nota projetada. Em relação ao município de Soure, as notas observadas encontram-se num valor bem abaixo das notas nacionais, mas nem tanto em relação às notas estaduais, porém, ainda não alcançaram as metas estipuladas. As notas da Escola Gasparino são as mais baixas do município, tendo alcançado a projeção de notas apenas uma vez, na edição de $2007^{6}$.

Em relação aos resultados da escola na Prova Brasil, nos anos de 2007 e 2013, percebeuse um considerável avanço nas notas, entretanto, a mesma ainda não conseguiu alcançar um nível acima do 01, no qual se encontra desde a primeira edição de 2005. Segundo a descrição da tabela dos níveis de proficiência em língua portuguesa do $9^{\circ}$ ano, os alunos que se encontram no nível 01 são capazes de "reconhecer expressões características da linguagem (científica, jornalística, etc) e a relação entre expressão e seu referente em reportagens e artigos de opinião; inferir o efeito de sentido de expressões e opiniões em crônicas e reportagens "7

Apesar de o resultado desta última edição apresentar um aumento da nota em relação aos anos anteriores, a descrição desta apresenta dados preocupantes, pois o percentual de alunos que se encontram abaixo do nível 01 é consideravelmente alto, ficando a apenas $4,65 \%$ pontos

\footnotetext{
${ }^{6}$ Os dados que geram esses resultados são obtidos por meio das avaliações nacionais da educação básica (SAEB), acrescido de informações referentes à taxa média de aprovação percentual.

7 Tabela atualizada de escala de proficiência; disponível em: http://portal.inep.gov.br/web/saeb/escalas-deproficiencia
} 
percentuais para determinar o nível de proficiências dos alunos da escola. Alunos que se encontram nesse nível não conseguem identificar expressões ou opiniões explicitas nos textos. Segundo dados do INEP/MEC, cerca de $25 \%$ do alunado brasileiro (matriculados nos anos finais do ensino fundamental de escolas públicas) encontra-se nesse nível de proficiência em leitura; no Pará são cerca de $29.4 \%$

Os outros fatores utilizados para calcular o IDEB de uma escola são os dados referentes à aprovação dos alunos. Dentre as informações prestadas, o que chama a atenção é a quantidade de alunos evadidos; esta realidade vem se prolongando há muitos anos na escola. Em algumas séries, especificamente do turno da tarde, o número de reprovação foi maior que o de aprovação, o que também representa um dado muito preocupante.

\subsection{A pesquisa em sala de aula: observações sobre os dados e os resultados}

De modo geral, as informações apresentadas no tópico anterior correspondem aos dados avaliativos das edições da Prova Brasil até o ano de 2013, e dados referentes às estatísticas anuais da escola; os dados que serão apresentados agora correspondem à pesquisa em sala de aula, realizada em 2014, o que não inclui os alunos nos dados apresentados sobre as notas da Prova Brasil, realizada a última vez em 2013. Entretanto, de acordo com as observações realizadas nas turmas de $8^{\mathrm{a}}$ série, a realidade atual não parece muito distante da encontrada há um ano.

De acordo com as considerações das professoras, os alunos apenas conseguem realizar atividades simples de leitura e compreensão do texto, quando estas tratam apenas do explícito; no que tange a realização de inferências, as dificuldades apresentadas são muitas.

Durante a observação das aulas, pôde-se notar também que as atividades realizadas com o texto são ainda muito focalizadas no conteúdo gramatical, sendo este utilizado como pretexto para a realização de atividades metalinguísticas, do tipo: "retire cinco substantivos concretos do texto". No decorrer da pesquisa, foram realizadas conversas individuais com as professoras e, apresentou-se a elas, algumas considerações sobre o trabalho com texto, considerando-se, na verdade, os gêneros textuais; e, sobre esta situação, a grande preocupação das docentes acabava sendo: e a gramática?

Neste momento foi sugerida, às professoras, a realização do diário, para que se pudesse tomar conhecimento da verdadeira forma como vinham conduzindo suas aulas. Infelizmente, apenas uma professora realizou a atividade e, de fato, demonstrou interesse em participar da 
pesquisa. Em razão disso, a parte da proposta de intervenção que foi executada só ocorreu na turma desta professora. As considerações a seguir dizem respeito ao diário da professora da turma C.

\title{
4.4.1 Dos dados obtidos
}

A professora da turma $\mathrm{C}$ demonstrou, em sua declaração, uma grande preocupação com o cumprimento dos conteúdos curriculares, que correspondem ativamente a preceitos gramaticais. Na verdade, essa preocupação é geral para todos os professores da escola, não só da disciplina de Língua Portuguesa, e sim todas; não que seja cobrado pelos coordenadores e gestão da escola, mas porque já é algo habitual para os docentes. No que diz respeito à sua prática de sala de aula, no trato com os conteúdos e seu repasse aos alunos, a professora declarou que o faz de modo objetivo, enfatizando os conceitos e as regras metalinguísticas. Em relação ao trabalho com o texto, a professora admite que não o faz do modo como gostaria, e declara suas dificuldades na manutenção de seu pensamento em relação ao ensino de língua materna.

\begin{abstract}
A minha forma de trabalhar os conteúdos é bastante direta, isto é, vou diretamente aos conceitos.[...]. Depois, trabalho com as atividades, é a partir delas que eu confirmo se realmente eles estão aprendendo, quando percebo que não, procuro explicar novamente o conteúdo. As minhas atividades são produzidas a partir de pesquisas feitas em livros didáticos, gramáticas normativas e também na internet. [...] Muitas vezes utilizo textos, mas confesso que, na maioria das vezes, estes são utilizados somente para fins gramaticais. Gostaria de trabalhar de forma diferente, porque sinto que estou fazendo "errado", mas eu também me vejo perdida e não sei como fazer o "certo". (Diário da professora - anexos da dissertação - p. 140)
\end{abstract}

A realidade da professora da turma $\mathrm{C}$ é a mesma de muitos educadores. O docente se incomoda com a forma rotineira e mecânica de ensinar porque vê, em seus alunos, que esse método não traz resultados; pelo contrário, acaba afastando-os mais ainda da vontade de aprender. Por outro lado, sabe da necessidade do repasse de regras gramaticais, para que o aluno tenha a sua linguagem aprimorada, e para que possa lidar com várias situações de uso desta, mas não sabe como mediar as duas coisas; como ensinar a língua de modo prazeroso e eficiente.

O que se nota na declaração da professora se encaixa no que já vinha sendo discutido, em relação ao modo como a maioria dos professores exercem suas práticas de sala de aula, no que tange à disciplina de língua portuguesa. 


\section{Proposta de Intervenção}

Após a realização do diário da professora e de alguns encontros para discutir suas inquietações, pôde-se fazer uma avaliação dos primeiros dados obtidos na pesquisa, e, uma vez detectados os principais pontos que se apresentavam como problema para o ensino, pôde-se passar à elaboração da proposta de intervenção, que enfocaria, principalmente, as seguintes questões: texto enquanto objeto de ensino (o ensino deveria partir do texto, oral ou escrito, e não utilizá-lo como mero suporte para a metalinguagem), e redirecionamento do ensino de gramática (uma espécie de contextualização da gramática, sua utilização enquanto um dos meios de realização da atividade discursiva do aluno).

A proposta de intervenção constitui-se da execução dessa nova perspectiva de ensino, que trabalha os gêneros textuais por meio de sequências didáticas; e, como meio de verificação da viabilidade desta, realizou-se, no segundo momento da pesquisa uma preliminar da proposta de intervenção, que correspondeu a uma sequência didática do gênero artigo de opinião. Esse modelo de atividade consistia de uma sequência de tarefas, que objetivava o ensino de um gênero textual, e seguia a linha de desenvolvimento consecutivo, onde os pontos que seriam abordados, seja de cunho textual ou gramatical, partiriam daquilo que fosse apresentado nas produções dos alunos, que seria o pontapé inicial para a realização da atividade.

Foi repassado à professora os primeiros passos da sequência, que correspondiam à apresentação da situação e proposta da produção inicial; em seguida, após esse primeiro momento, a professora realizou a correção dos textos, como habitualmente fazia, e, seguindo as orientações recebidas, passou a observar as questões relativas às características do gênero.

De modo geral, pode-se dizer que as atividades realizadas foram muito produtivas, frente aos resultados obtidos. A produção final apresenta um significativo amadurecimento dos alunos, o que mostra que as informações dadas durante a sequência foram assimiladas em sua maioria, e mais, o modo como todo o processo foi conduzido (mesmo quando era necessário realizar o repasse de conteúdos gramaticais), não foi algo cansativo e enfadonho, nem para a professora e nem para alunos.

Dessa maneira, pode-se dizer que os resultados estão dentro do que era esperado, visto que os alunos não tinham o hábito de realizar atividades de produção de texto, e o ensino de gramática costumava ser o único foco nas aulas e, apesar disso, ainda assim o número de incidência de desvios gramaticais foi muito alto, o que mostra que, um ensino baseado apenas 
na metalinguagem (como, em geral, é feito por muitos professores) é insuficiente para a formação dos alunos.

Segundo Antunes,

A gramática é um dos componentes de que se constitui uma língua. Um dos componentes, bem entendido. Não é o único nem o mais importante. Forma, com o léxico, a matéria que se concretiza em produções verbais, que, são, na verdade, ações verbais. Tem fundamental importância. É necessária. Mas, o exercício da atividade verbal requer muito mais do que o concurso da gramática.[...] (ANTUNES, 2014, p.

24. Grifos da autora)

Nas palavras da autora, “a gramática é necessária, mas não é suficiente” (ANTUNES, 2014, p.27). Essa é uma realidade que, apesar de vir sendo debatida exaustivamente por muitos estudiosos da área, há muito tempo, ainda representa algo muito distante para diversos educadores, mas, que tende a se propagar; pelo menos é o que se almeja.

$\mathrm{Na}$ avaliação final da atividade realizada pela professora da turma $\mathrm{C}$, muita coisa mudou, não só para os alunos que finalmente tiveram prazer em aprender, ou em fazer um texto, mas, nas concepções da docente que, imbuída de um sentimento de mudança, tem buscado novas informações a respeito da concepção interacionista da língua, do trabalho com os gêneros, de uma nova maneira de ensinar.

\section{Teorias que fundamentam a proposta}

Durante muitos anos se pensou o ensino de uma forma normalista e prescritivista, onde se privilegiava a chamada norma culta $^{8}$, e para isso, o modelo escolhido foi o da língua usada por pessoas que detinham um alto grau de instrução escolar, sendo escritores ou estudiosos conceituados.

Entretanto, no decorrer dos anos, muitos estudos têm sido realizados com o intuito de desmistificar a ideia de que só existe uma forma de utilizar a língua (que seria a culta); nesse sentido, a sociolinguística é uma das áreas de atuação que mais tem contribuído. Munidos desse saber, vários estudiosos da língua, em parceria com os governos, que ditam as leis educacionais, têm unido forças para promover um ensino que não seja exclusivamente direcionado ao repasse da norma culta, mas que possibilite ao aluno desfrutar de uma diversidade maior de variantes

\footnotetext{
${ }^{8}$ Sobre este termo cabe uma necessária reflexão, uma vez que sua conceituação tem causado, por vezes, uma certa confusão, em função das várias definições que recebe. Sobre esse assunto pode-se consultar Bagno 2003, Faraco, 2008; entre outros.
} 
linguísticas, ou seja, que envolva os alunos nas mais variadas situações de fala, conscientizando estes da adequação linguística de cada situação comunicativa.

Entretanto, sendo a norma culta a variante da língua que detém maior prestígio em razão de seu valor social, é importante que seja ensinada na escola, mas sem que se imponha a mesma em detrimento das demais, pois, apesar de seu reconhecido valor social, ainda assim ela é "uma" variante, e como tal, deve ser utilizada de acordo com a situação comunicativa que ancora os falantes, para que de fato seja bem utilizada.

De modo geral, o que é preciso para se chegar a um ensino significativo é, antes, eleger uma ou outra variante, reconhecer os aspectos semânticos e pragmáticos que envolvem a comunicação, ou seja, o que há por trás do texto que se produz (seja ele oral ou escrito), qual seu valor enunciativo, e quem são os seus interlocutores. Em outras palavras, não adianta ensinar regras gramaticais, se o texto que se lê ou se produz não tem sentido para o aluno, se ele não o compreende perfeitamente.

Dentro dessa perspectiva, uma teoria que ampara de modo eficiente essa proposta é a do Interacionismo Sócio Discursivo, a qual é amplamente discutida por Bronckart (1999). Em linhas gerais, o Interacionismo Sócio Discursivo é um quadro teórico que entende as condutas humanas como “"ações situadas' cujas propriedades estruturais e funcionais são, antes de mais nada, um produto da socialização" (BRONCKART, 1999, p.13).

Bronckart (1999) elaborou, a partir da concepção interacionista da linguagem, uma série de considerações didáticas para o ensino, as quais levavam em consideração a teoria dos gêneros, desenvolvida por Bakhtin (1979). Bronckart desenvolveu um estudo de linha teórica procedente aos princípios do Interacionismo social, o chamado Interacionismo Sócio Discursivo (ISD).

Em seus estudos, lançando um olhar mais direcionado ao conteúdo educacional, Bronckart questiona a eficácia de um ensino que desconsidera as reais situações de comunicação, que se baseie apenas em fragmentos da língua (recurso muito utilizado no ensino tradicional), entretanto, não desmerece o ensino da gramática, saber necessário para a articulação da língua em suas diversas manifestações. O que o autor defende é um ensino contextualizado, que considere o caráter interacionista da língua, e que parta de situações reais de uso linguístico, e não apenas de situações hipotéticas e ideais, por isso sua recomendação na prática do ensino de língua é que ela se realize por meio de gêneros textuais. 
A teoria dos gêneros do discurso, por sua vez, foi desenvolvida por Mikhail Bakhtin no início do século XX, aproximadamente em 1929, mas ganhou maior proporção no ano de 1979. O autor, ao considerar a ligação concreta entre a linguagem e toda e qualquer atividade humana, concluiu que, tanto quanto hajam diferentes formas de se realizar ações humanas, também haverá diversas maneiras de uso da linguagem. Essa atividade, que constitui o emprego real de uma língua, realiza-se, segundo Bakhtin, por meio de enunciados, sejam eles orais ou escritos, efetuados em todos os campos da comunicação humana, por todos os usuários da língua.

Tais enunciados compreendem, em sua totalidade, as condições próprias da comunicação, como, objetivos, estilo, escolhas linguísticas, etc; todos esses fatores, agrupados em um texto, correspondem ao que o autor denominou gêneros do discurso.

Todos esses elementos - o conteúdo temático, o estilo, a construção composicional estão indissoluvelmente ligados no todo do enunciado e são igualmente determinados pela especificidade de um determinado campo da comunicação. Evidentemente, cada enunciado particular é individual, mas cada campo de utilização da língua elabora seus tipos relativamente estáveis de enunciados, os quais denominamos gêneros do discurso. (BAKHTIN, [1979] 2011, p. 262 - grifos do autor)

Os gêneros discursivos, posteriormente denominados pelos seguidores das ideias de Bakhtin como gêneros textuais, não compreendem "modelos" de textos, pois não são definidos e fechados, modificam-se conforme a emergência da comunicação humana, daí a definição de Bakhtin sobre eles, "tipos relativamente estáveis" de enunciados, que surgem em função das várias ações humanas. É como se fossem grupos de textos que apresentam características comuns, mas que não se limitam a um único padrão. Podem ser assim definidos por constituírem atividades sócio discursivas, fruto de fenômenos sócio históricos, e sensíveis culturalmente; portanto, passíveis de se modificar e adaptar.

Segundo Bronckart (1999, p. 103), “a apropriação dos gêneros é, por isso, um mecanismo fundamental de socialização, de inserção prática nas atividades comunicativas humanas", ou seja, surgem em meio às situações de urgência e emergência linguística, que não correspondem a uma forma linguística propriamente dita, mas a uma forma de realizar a comunicação humana, levando em conta seus objetivos e finalidades. Desse modo, é possível concluir não só o caráter estável e variável dos gêneros, mas seu caráter criador, enquanto meio de se retomar a linguagem e, ao mesmo tempo, fazê-la evoluir. Quanto a isto, Bakhtin reforça o caráter heterogêneo dos gêneros. 
A riqueza e a diversidade dos gêneros do discurso são infinitas porque são inesgotáveis as possiblidades da multiforme atividade humana e porque em cada campo dessa atividade é integral o repertório de gêneros do discurso, que cresce e se diferencia à medida que se desenvolve e se complexifica um determinado grupo. (BAKHTIN, [1979] 2011, p. 262)

Sendo assim, os gêneros podem ser definidos pelo que as pessoas reconhecem que eles sejam, a partir de seus usos, e emergem dos processos sociais em que os sujeitos estão inseridos, sejam eles retóricos, culturais, institucionalizados etc. Os gêneros, neste caso, proporcionam limites, transformações e realizações que constroem sentidos nas atividades humanas, e que introduzem práticas discursivas de usos em situações cotidianas veiculadas pela ativação do controle social, do exercício de poder, da organização das atividades humanas etc.

A partir das ideias de Bakhtin, muito estudiosos aprofundaram suas pesquisas sobre os gêneros textuais, obtendo-se assim, uma grande gama de trabalhos, que hoje servem de base para muitos suportes didáticos. Dentre estes trabalhos, chama-se a atenção para os estudos desenvolvidos por Dolz e Schneuwly (2004), que elaboraram, entre os anos de 1994 e 1997, um instrumental muito eficiente, segundo os mesmos, no trabalho com gêneros textuais para a escola básica, a sequência didática, a qual foi utilizada pelos autores para elaboração de material didático em suas experiências docentes.

Para os autores, o ensino de textos baseado no conceito de gêneros possibilita aos alunos um maior acesso à cultura linguística de um país e, consequentemente, um melhor domínio da comunicação oral e escrita, nas mais diferentes situações de uso da língua. Os autores assim definem o procedimento Sequência Didática: "Uma 'sequência didática' é um conjunto de atividades escolares organizadas, de maneira sistemática, em torno de um gênero textual oral ou escrito" (DOLZ e SCHNEUWLY, 2004, p. 82).

A justificativa para um trabalho que parta do texto, ou seja, que tenha no texto seu objeto de ensino, pauta-se na concepção sócio interacionista da linguagem, que reconhece a escolha do texto, ou o nível de formalidade da linguagem, de acordo com a situação de interação na qual se inserem os falantes, bem como, avalia esses, seus interesses, expectativas, intenções, etc. Como já antecipava Bakhtin, a linguagem do indivíduo advém de sua vontade discursiva, e é isto que determina a escolha por este ou aquele gênero textual. Segundo o autor, tal escolha se faz em face das características que configuram o campo da comunicação discursiva, a temática subjacente a ela e, as especificidades de seus participantes.

O objetivo da sequência didática é possibilitar ao aluno dominar as características de um determinado gênero e, tendo em vista seu caráter heterogêneo e variável (apesar de sua 
estabilidade), ser capaz de identificar o porquê de tais características, sejam elas linguísticas, de estilos ou temáticas. "Uma sequência didática tem, precisamente, a finalidade de ajudar o aluno a dominar melhor um gênero de texto, permitindo-lhe, assim, escrever ou falar de uma maneira mais adequada numa dada situação de comunicação" (DOLZ e SCHNEUWLY, 2004, p. 83). Em suas considerações, os autores recomendam que o trabalho escolar deve ser focalizado sobre os gêneros que os alunos menos têm contato, que são mais inacessíveis a eles, bem como aqueles que circulam em esferas públicas e privadas, para que os alunos tenham acesso a novas práticas de linguagem.

\section{Apresentação \\ da situação}

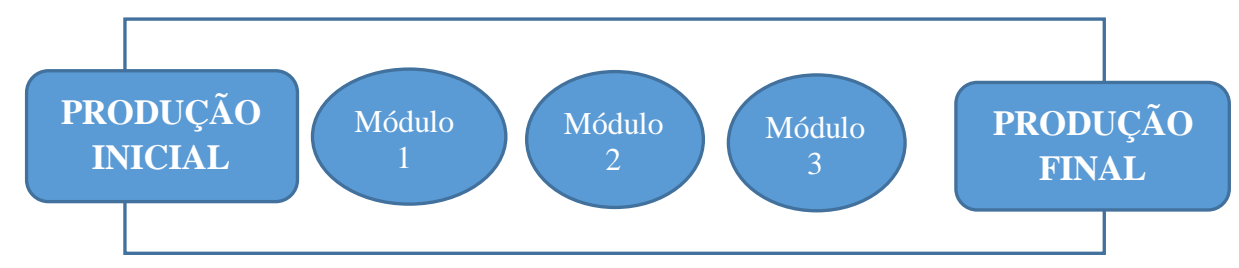

Esquema da Sequência Didática (DOLZ e SCHNEUWLY, 2004)

$\mathrm{Na}$ apresentação inicial ocorre a realização de duas dimensões linguísticas: primeiramente, expõe-se, ao aluno, o objeto de seu estudo, o projeto de comunicação que será realizado. Nesse momento, tem-se a construção da situação comunicativa que ampara aquele evento linguístico: o gênero que será produzido, as características dos interlocutores, expectativas sobre a comunicação, suporte do gênero, etc. Em seguida, organiza-se a dimensão dos conteúdos dos textos que serão produzidos. Nesta etapa, estuda-se a natureza temática dos textos, suas características semânticas e, seus objetivos comunicativos, por exemplo, o que se espera de uma carta argumentativa?

Segundo os autores, "a fase inicial da situação permite, portanto, fornecer aos alunos todas as informações necessárias para que conheçam o projeto comunicativo visado e a aprendizagem de linguagem a que está relacionado" (DOLZ e SCHNEUWLY, 2004, p. 85). 
Dolz e Schneuwly lembram ainda que, as sequências didáticas devem abordar uma situação comunicativa que seja, de fato, significativa, ou seja, que represente algo real para os alunos, apresentando-lhes um retorno.

Após a apresentação inicial, passa-se a sugestão de uma primeira produção, já sobre o gênero que será abordado. Nessa fase, os alunos irão dispor apenas de informações primárias sobre a atividade discursiva que irão produzir, os conhecimentos que já possuem e as informações obtidas da apresentação inicial realizada pelo professor. É a partir da produção inicial que o docente terá suporte para construir os módulos da sequência, pois, uma vez que os alunos produzam seus textos apenas com o conhecimento que já possuem, o professor poderá observar o que ainda é necessário para que os mesmos dominem mais completamente o gênero estudado e, consequentemente, fixar melhor certos pontos ou reiterar outros, de acordo com o nível dos alunos.

\footnotetext{
Por meio da produção, o objeto da sequência didática delineia-se melhor nas suas dimensões comunicativas e também se manifesta como lugar de aprendizagem necessária das dimensões problemáticas. Assim, a sequência começa pela definição do que é preciso trabalhar a fim de desenvolver as capacidades de linguagem dos alunos que, apropriando-se dos instrumentos de linguagem próprios ao gênero, estarão mais preparados para realizar a produção final. (DOLZ e SCHNEUWLY, 2004, p. 87)
}

Após a avaliação das produções iniciais dos alunos, o professor passará a construir os módulos, que correspondem às fases da sequência que serão desenvolvidas durante as aulas, no sentido de sanar os "problemas" apresentados pelos discentes em suas primeiras produções. A organização desses módulos deve compreender uma abordagem que parta daquilo que é mais complexo para o que é, aparentemente, mais simples e, ao final dela, volta-se ao momento de alta complexidade novamente, que é a produção final.

Durante a realização dos módulos, o professor irá abordar o que julga mais importante para a aprendizagem dos alunos, por isso, não há como se definir algo com muita antecedência (como em geral se faz na elaboração de grades curriculares). Os conteúdos que serão abordados no módulos são determinados a partir das necessidades dos alunos, devendo ser discutidos de acordo também com as características do gênero estudado.

$\mathrm{O}$ professor deve, portanto, dar preferência às questões relacionadas ao bom desenvolvimento dos textos e conteúdos gramaticais que auxiliem esse desenvolvimento, de modo a levar os alunos a dominarem não só as características do gênero que ora estudam, como também, a dominarem sua própria linguagem; para que, futuramente, possam fazer uso desta 
de uma maneira mais completa, natural e eficiente, para usá-la adequadamente e, saber, principalmente, quando ela está mal-empregada.

O fechamento da sequência consiste na produção final, momento no qual se coloca em prática tudo o que foi aprendido nos módulos. Os alunos, nessa fase, irão reescrever suas produções iniciais.

Em relação à avaliação, os autores recomendam que ela se realize também dentro da perspectiva dos alunos, para que eles mesmos possam verificar suas evoluções, indicando o que foi aprendido, o que ainda resta aprender, de que modo se deu seus progressos, e, como se comportam enquanto produtores de textos, considerando sua revisão e reescrita.

Essas conclusões são observadas durante toda a realização da sequência, e, mais especificamente no momento da produção final, em geral, por meio da lista de constatações. Nesta lista, ou grade, alunos e professores, detectam os elementos trabalhados na sequência, que constituem seus critérios de avaliação.

A grade de avaliação serve ainda para que os professores centrem suas intervenções nos pontos mais importantes da sequência. "Assim, a grade serve, portanto, não só para avaliar num sentido mais estrito, mas também para observar as aprendizagens efetuadas e planejar a continuação do trabalho, permitindo eventuais retornos a pontos mal assimilados”. (p. 91)

\section{Exemplo de grade de avaliação do gênero Artigo de Opinião}

\begin{tabular}{|c|c|c|}
\hline CRITÉRIOS & ESTÁ OK & $\begin{array}{c}\text { DEVE } \\
\text { MUDAR }\end{array}$ \\
\hline 1. Adequação do título & & \\
\hline $\begin{array}{l}\text { 2. Adequação ao contexto de produção de linguagem: } \\
\text { - A questão discutida é mesmo controversa e de relevância social? }\end{array}$ & & \\
\hline $\begin{array}{l}\text { - Você, enquanto autor, se colocou como alguém que discute a questão } \\
\text { racionalmente, considerou o leitor e o veículo de publicação do texto? }\end{array}$ & & \\
\hline $\begin{array}{l}\text { - Considera que conseguiu atingir seu objetivo de tentar convencer seus } \\
\text { leitores? }\end{array}$ & & \\
\hline $\begin{array}{l}\text { 3. Estrutura do texto: } \\
\text { • Introdução: houve contextualização adequada da questão discutida? }\end{array}$ & & \\
\hline $\begin{array}{l}\text { - Desenvolvimento: houve explicitação da posição defendida perante a } \\
\text { questão, e uso de argumentos para defender a posição assumida. }\end{array}$ & & \\
\hline - Conclusão: presença de uma conclusão adequada. & & \\
\hline $\begin{array}{l}\text { 4. Argumentação: } \\
\text { - Seleção de informações relevantes. }\end{array}$ & & \\
\hline $\begin{array}{l}\text { 5. Marcas linguísticas: } \\
\text { • Emprego adequado de unidades coesivas (próprios da argumentação). }\end{array}$ & & \\
\hline - Adequação das normas gramaticais & & \\
\hline - Abandono de formas típicas da oralidade & & \\
\hline - Legibilidade (grafia, ausência de rasuras, etc) & & \\
\hline 6. Revisão: releitura do texto pronto & & \\
\hline
\end{tabular}


No decorrer do estudo sobre as sequências didáticas desenvolvido por Dolz e Schneuwly, pode-se encontrar ainda diversas orientações a respeito de como as sequências podem ser desenvolvidas, bem como, algumas considerações sobre a base teórica que as sustenta, e os pontos que devem ser considerados quando se proceder a organização dos módulos.

\section{Considerações Finais}

O ensino de língua materna, atualmente, constitui-se em uma das grandes preocupações das políticas públicas nacionais, pois representa um dos principais itens por meio do qual se pode almejar a melhoraria da qualidade de ensino do país. Entretanto, apesar dos consideráveis avanços que muitas iniciativas, públicas e privadas, têm apresentado, ainda há muita coisa a se fazer.

Dentre essas muitas coisas, está a necessidade de se incorporar uma concepção de língua menos distante da realidade diária do aluno. Isto não significa que não se vai ensinar a gramática ou a norma culta. Significa sim que a língua formal será ensinada por meio e estratégias menos díspares da realidade linguística do usuário da língua.

Nesse caso, é interessante que toda e qualquer iniciativa que possa vir a colaborar para a melhoria do ensino parta da própria sala de aula, mesmo que se proponha a mudar apenas uma realidade (uma comunidade escolar). Neste sentido, dentre as discussões levantadas neste estudo, questionou-se o modo como o ensino de língua materna tem sido conduzido na maioria das escolas brasileiras, em face dos resultados das avaliações nacionais que indicam um baixo nível de competência linguística dos alunos.

Geralmente, quando os alunos iniciam sua vida escolar, deparam-se com uma realidade linguística diferente da sua, onde, primeiro, precisam aprender que aquilo que falam pode também ser escrito, mas nem sempre os sons que reproduzem correspondem aos símbolos que devem utilizar na escrita. E, a partir disso, inicia-se uma série de aplicações (e, por vezes, imposições) de regras e normas que, cada vez mais, distanciam os alunos da língua que dominam. Entretanto, eles não param de utilizá-la; em casa, no convívio familiar e em outros ambientes, os alunos continuam a se valer da língua que dominam, e entram em choque quando lhes é cobrada a utilização da língua que a escola ensina. 
Isso acarreta diversos problemas, pois, apesar de os professores buscarem ensinar a seus alunos as regras da gramática normativa, os mesmo não a veem como algo útil para a sua vida, e, talvez, por essa razão, não se empenhem em aprendê-la e exercitá-la.

O que se quer dizer com isso é que um ensino que priorize apenas as regras gramaticais exclui os alunos que não as dominam e, consequentemente, atrasa a aprendizagem.

Nesse sentido, cabe ao professor de língua materna de todos os níveis de ensino assumir uma postura mais consciente e engajada, que promova a aprendizagem dos alunos a partir do conhecimento que eles já trazem de casa e, possam, paulatinamente, introduzir novos conhecimentos, sem desmerecer o domínio linguísticos dos alunos. Esse tipo de postura aproxima mais alunos e professores, pois proporciona uma interação maior, até mesmo porque, utiliza os conhecimentos que os alunos já possuem, mostrando uma aplicabilidade destes dentro do processo de ensino e aprendizagem.

Desse modo, para que o ensino de língua materna chegue a um bom grau de eficiência, algumas questões muito importantes, que foram tratadas neste estudo, devem ser relembradas e levadas em consideração.

Primeiramente, que se considere, dentro das posturas educacionais que as escolas venham a assumir, que a ideia de que o aluno aprende a ler e a escrever apenas nas séries iniciais é infundada, ao menos, de acordo com a visão que se tem atualmente. Como foi discutido aqui, o período denominado de alfabetização é responsável pela aquisição das capacidades de codificar e decodificar os signos, ou seja, ler e escrever; mas, a conscientização desses atos se concretiza com as práticas de letramento, que fundamentam e incorporam as atividades mecânicas de codificação e decodificação. Ou seja, não basta ao aluno apenas saber ler e escrever, é preciso que ele atribua sentido ao que está lendo e escrevendo, até porque, este processo está sempre em constante amadurecimento, não se findando ao término do ciclo da alfabetização.

Desse modo, acredita-se que, para que se alcance uma aprendizagem realmente significativa desde o início da vida escolar de um indivíduo, é necessário que o processo educacional se inicie com a aplicação dos meios de alfabetização, atrelados à noção de letramento, a qual deverá se estender em todos os anos escolares deste indivíduo, pois é o que vai lhe possibilitar a conscientização de que seu discurso possui significado e, portanto, tem um que e um porquê; ou seja, uma razão de ser. 
Essa postura educacional se liga à filosofia interacionista da linguagem, que considera as relações existentes entre os interlocutores, seus objetivos e expectativas, e seu ambiente de comunicação.

Por essa razão, este trabalho apresentou como sugestão de trabalho, uma proposta baseada nos princípios do Interacionismo Sócio Discursivo, e que considera o texto como principal objeto de ensino, no que se refere à disciplina de Língua Portuguesa.

Estudar os textos, dentro da concepção interacionista permite aos alunos a conscientização dos valores que suas escolhas têm. Quando se optar por um determinado gênero textual, não se faz uma escolha aleatória, existe, por trás dessa ação, uma postura responsiva e capaz de realizar os objetivos linguísticos do falante. As escolhas feitas por eles são fruto de sua vontade discursiva, que é construída a partir da postura criativa da língua, que se fundamenta desde o início de sua vida escolar, quando os alunos são incentivados por meio das práticas de letramento.

O ensino de gêneros é um dos meios que leva os alunos a assumirem suas posturas responsivas frente às capacidades linguísticas que desejam realizar, além de representarem uma crescente ação junto à concepção de que a língua evolui, assim como seus falantes.

E, para que esse ensino chegue aos alunos de modo eficiente e concreto, um instrumento bastante eficaz é a sequência didática, proposta por Dolz e Schneuwly (2004), que vem sendo reproduzida e adaptada por várias escolas. Sua eficiência e aplicabilidade ficaram comprovadas na demonstração da proposta didática apresentada neste trabalho que ora se encerra. A evolução dos alunos, apesar de singela, foi bastante significativa e o nível de satisfação dos docentes demonstra o quanto é válida a execução da proposta.

De modo geral, após todas as discussões que foram realizadas e debatidas aqui, a conclusão final a que se chega é que, o ensino de língua materna deve envolver atividades que visem o desenvolvimento de comportamentos e habilidades de uso da língua em práticas sociais, ou seja, é necessário que ocorram práticas de letramento, não só na alfabetização (mas a partir desta), como em todos os níveis de ensino pelos quais passa uma pessoa. Percebe-se assim a importância de se ter um ensino desenvolvido dentro do contexto de práticas sociais de leitura e escrita.

Contudo, é necessário que essa concepção faça parte da vida dos professores e da escola como um todo, bem como sejam dados maiores incentivos governamentais que visem o 
aperfeiçoamento dos profissionais da área, que, por sua vez, também devem buscar esse aperfeiçoamento.

Em suma, deseja-se que, de posse dos conhecimentos necessários, alunos e professores possam desempenhar melhor seus papéis, não apenas enquanto membros de uma comunidade escolar, mas como membros de uma sociedade, e que esta possa proporcionar oportunidades iguais àqueles que dela fazem parte.

\section{Referências}

ANTUNES, Irandé. Gramática contextualizada: limpando "o pó das ideias simples". São Paulo: Parábola, 2014

BAKHTIN, Mikhail (V.N. Volochinov). Marxismo e filosofia da linguagem. Trad. Michel Lahud e Yara Frateschi Vieira. 6 ed. São Paulo: Hucitec, 1992 [1929]

BAKHTIN, Mikhail M. Estética da criação verbal. Trad. Paulo Bezerra. 6 ed. São Paulo: WMF Martins Fontes, 2011 [1979]

BAZERMAN, Charles. Gêneros textuais, tipificação e interação. Angela Paiva Dionísio e Judith Chambliss Hoffnagel (orgs.) Trad. e adap. Judith Chambliss Hoffnagel. 4 ed. São Paulo: Cortez, 2011

BORTONI-RICARDO, Stella Maris; MACHADO, Veruska Ribeiro; CASTANHEIRA, Salete Flôres. Formação do professor como agente letrador. São Paulo: Contexto, 2010

BRONCKART, Jean-Paul. Atividade de linguagem, textos e discursos: por um interacionismo sociodiscursivo. Trad. Anna Rachel Machado e Péricles Cunha. 2 ed. São Paulo: EDUC, 1999

CAGLIARI, Luiz Carlos. Alfabetização e linguística. 10 ed. São Paulo: Scipione, 1997

CASTILHO, Ataliba T. de; ELIAS, Vanda Maria. Pequena gramática do Português Brasileiro. São Paulo: Contexto, 2012

DOLZ, Joaquim; GAGNON, Roxane; DECÂNDIO, Fabrício. Produção escrita e dificuldades de aprendizagem. Adap. Joaquim Dolz e Fabrício Decânio. Trad. Fabrício Decânio e Anna Rachel Machado. Campinas, SP: Mercado de letras, 2010

DOLZ, Joaquim; Schneuwly, Bernard. Gêneros orais e escritos na escola. Trad. e org. Roxane Rojo e Glaís Sales Cordeiro. 3 ed. Campinas, SP: Mercado de letras, 2004

FARACO, Carlos Alberto. Norma culta brasileira: desatando alguns nós. São Paulo: Parábola, 2008

FERRAREZI JR., Celso; CARVALHO, Robson Santos de. Produzir textos na educação básica: o que saber, como fazer. São Paulo: Parábola, 2015 
FERREIRA, Débora Cristina do Nascimento; RODRIGUES, Isabel Cristina França dos Santos; LEAL, Rita de Cássia Macedo. Trabalho docente e didatização de gêneros discursivos: desafios e avanços no ensino de português para turmas numerosas. In GOMES-SANTOS, Sandoval Nonato; BENTES, José Anchieta de Oliveira; ALMEIDA, Patrícia Sousa (orgs.). Trabalho docente e linguagem: em diferentes contextos escolares. Belém, PA: Paka-Tatu, 2014

FERREIRO \& TEBEROSKY, Emília; Ana. Psicogênese da língua escrita. Porto Alegre: Artmed, 1999

FRANCO, M. A. R. S. A pedagogia da pesquisa-ação. In: Encontro Nacional de Didática e Prática de Ensino, 12, 2004, Curitiba. Anais. Curitiba: Endipe, 2005

KATO, Mary A. No mundo da escrita: uma perspectiva psicolinguística. 2 ed. São Paulo: Ática, 1987

KLEIMAN, Angela B. (org.). Os significados do letramento: uma nova perspectiva sobre a prática social da escrita. 2 ed. Campinas, SP: Mercado das letras, 2012

KLEIMAN, Angela B.; MATENCIO, Maria de Lourdes Meirelles (orgs.). Letramento $e$ formação do professor: práticas discursivas, representações e construção do saber. Campinas, SP: Mercado das letras, 2005

LEMLE, Miriam. Guia teórico do alfabetizador. 17 ed. São Paulo: Ática, 2011

MEC (Ministério da Educação). Instituto Nacional de Estudos e Pesquisas Educacionais. SAEB 2001: novas perspectivas / Instituto Nacional de Estudos e Pesquisas Educacionais. - Brasília: O Instituto, 2001. 2012 Pacto Nacional pela Educação na Idade Certa (Livreto do pacto). Brasília: O Instituto,

NAIDITCHF, F. Pesquisa - ação. In: OLIVEIRA, D.A.; DUARTE, A.M.C.; VIEIRA, L.M.F. DICIONÁRIO: trabalho, profissão e condição docente. Belo Horizonte: UFMG/Faculdade de Educação, 2010. CDROM

NEVES, Maria Helena de Moura. Que gramática estudar na escola?: norma e uso na Língua Portuguesa. 4 ed. São Paulo: Contexto, 2013

PERINI, Mário A. Gramática do Português brasileiro. São Paulo: Parábola, 2010

ROJO, R. (Org.). A prática da linguagem em sala de aula: praticando os PCN. São Paulo: Educ; Campinas: Mercado de Letras, 2000

SILVA, Ademar da. Alfabetização, a escrita espontânea. 2 ed. São Paulo: Contexto, 1994

SOARES, Magda. Alfabetização e letramento. 6 ed. São Paulo: Contexto, 2013 Letramento: um tema em três gêneros. 3 ed. Belo Horizonte: Autêntica, 2012 
Letramento e escolarização. In: RIBEIRO, Vera Masagão (Org.). Letramento no Brasil: reflexões a partir do INAF 2001. São Paulo: Global, 2003. p.89-113

SOLÉ, Isabel. Estratégias de leitura. 6 ed. Porto Alegre, RS: Artmed, 1998

Recebido em 23 de julho de 2018. Aceito em 10 de setembro de 2018. 